Argonne

\title{
Testing of Strategies for the Acceleration of the Cost Optimization
}

Nuclear-Renewable Hybrid Energy Systems: Analysis of Technical \& Economic Issues

Nuclear Engineering Division 


\begin{abstract}
About Argonne National Laboratory
Argonne is a U.S. Department of Energy laboratory managed by UChicago Argonne, LLC under contract DE-AC02-06CH11357. The Laboratory's main facility is outside Chicago, at 9700 South Cass Avenue, Argonne, Illinois 60439. For information about Argonne and its pioneering science and technology programs, see www.anl.gov.
\end{abstract}

\title{
DOCUMENT AVAILABILITY
}

Online Access: U.S. Department of Energy (DOE) reports produced after 1991 and a growing number of pre-1991 documents are available free via DOE's SciTech Connect (http://www.osti.gov/scitech/)

Reports not in digital format may be purchased by the public from the National Technical Information Service (NTIS):

U.S. Department of Commerce

National Technical Information Service

5301 Shawnee Rd

Alexandria, VA 22312

www.ntis.gov

Phone: (800) 553-NTIS (6847) or (703) 605-6000

Fax: (703) 605-6900

Email: orders@ntis.gov

Reports not in digital format are available to DOE and DOE contractors from the Office of Scientific and Technical Information (OSTI):

U.S. Department of Energy

Office of Scientific and Technical Information

P.O. Box 62

Oak Ridge, TN 37831-0062

www.osti.gov

Phone: (865) 576-8401

Fax: (865) 576-5728

Email: reports@osti.gov

\footnotetext{
Disclaimer

This report was prepared as an account of work sponsored by an agency of the United States Government. Neither the United States Government nor any agency thereof, nor UChicago Argonne, LLC, nor any of their employees or officers, makes any warranty, express or implied, or assumes any legal liability or responsibility for the accuracy, completeness, or usefulness of any information, apparatus, product, or process disclosed, or represents that its use would not infringe privately owned rights. Reference herein to any specific commercial product, process, or service by trade name, trademark, manufacturer, or otherwise, does not necessarily constitute or imply its endorsement, recommendation, or favoring by the United States Government or any agency thereof. The views and opinions of document authors expressed herein do not necessarily state or reflect those of the United States Government or any agency thereof, Argonne National Laboratory, or UChicago Argonne, LLC.
} 


\section{Testing of Strategies for the Acceleration of the Cost Optimization}

Nuclear-Renewable Hybrid Energy Systems: Analysis of Technical \& Economic Issues

prepared by

Roberto Ponciroli and Richard B. Vilim

Nuclear Engineering Division, Argonne National Laboratory

August 31, 2017 
The general problem addressed in the Nuclear-Renewable Hybrid Energy System (N-R HES) project is finding the optimum economical dispatch (ED) and capacity planning solutions for the hybrid energy systems. In the present test-problem configuration, the N-R HES unit is composed of three electrical power-generating components, i.e. the Balance of Plant (BOP), the Secondary Energy Source (SES), and the Energy Storage (ES). In addition, there is an Industrial Process (IP), which is devoted to hydrogen generation. At this preliminary stage, the goal is to find the power outputs of each one of the N-R HES unit components (BOP, SES, ES) and the IP hydrogen production level that maximizes the unit profit by simultaneously satisfying individual component operational constraints.

The optimization problem is meant to be solved in the Risk Analysis Virtual Environment (RAVEN) framework. The dynamic response of the N-R HES unit components is simulated by using dedicated object-oriented models written in the Modelica modeling language. Though this code coupling provides for very accurate predictions, the ensuing optimization problem is characterized by a very large number of solution variables. To ease the computational burden and to improve the path to a converged solution, a method to better estimate the initial guess for the optimization problem solution was developed. The proposed approach led to the definition of a suitable Monte Carlo-based optimization algorithm (called the preconditioner), which provides an initial guess for the optimal N-R HES power dispatch and the optimal installed capacity for each one of the unit components. The preconditioner samples a set of stochastic power scenarios for each one of the N-R HES unit components, and then for each of them the corresponding value of a suitably defined cost function is evaluated. After having simulated a sufficient number of power histories, the configuration which ensures the highest profit is selected as the optimal one. The component physical dynamics are represented through suitable ramp constraints, which considerably simplify the numerical solving.

In order to test the capabilities of the proposed approach, in the present report, the dispatch problem only is tackled, i.e. a reference unit configuration is assumed, and each one of the N-R HES unit components is assumed to have a fixed installed capacity. As for the next steps, the main improvement will concern the operation strategy of the ES facility. In particular, in order to describe a more realistic battery commitment strategy, the ES operation will be regulated according to the electricity price forecasts. 


\section{Table of Contents}

Table of Contents.........................................................................................................

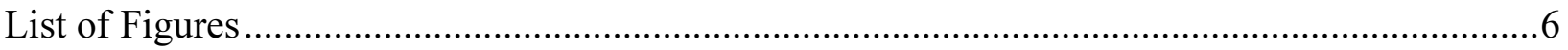

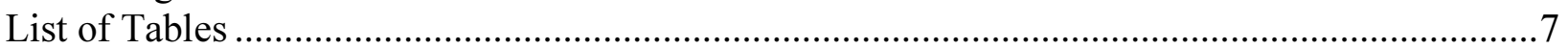

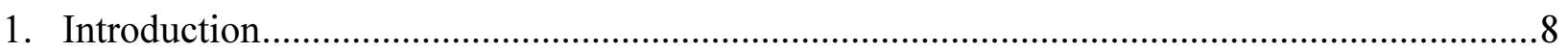

2. NHES unit parameters to be adopted into the Optimization Algorithm ................................ 9

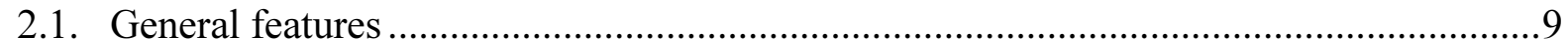

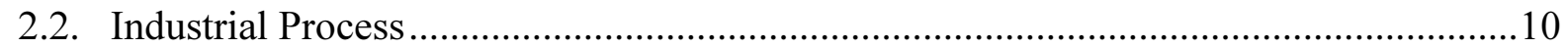

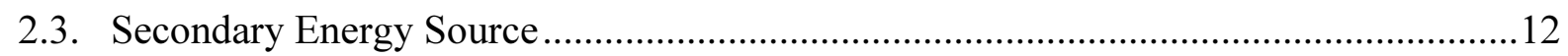

2.4. Balance of Plant ................................................................................................. 13

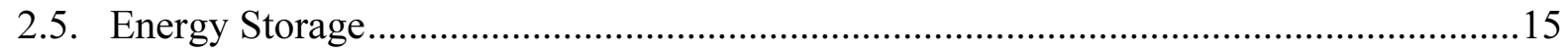

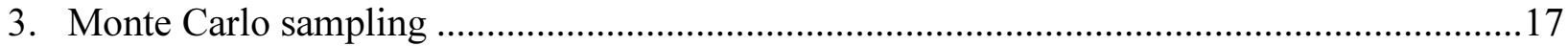

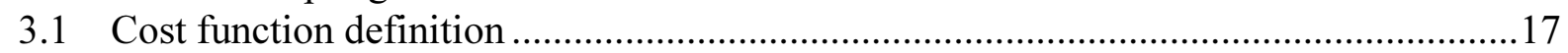

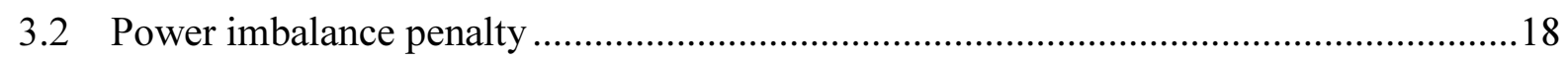

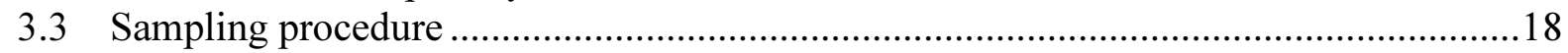

3.3.1. Sampling the BOP and the SES instantaneous power outputs .......................19

3.3.2. Definition of the ES operation mode and ES power output sampling...............19

3.3.3. Iterative constraint verification procedure ................................................20

3.3.4. Cost function evaluation ........................................................................ 21

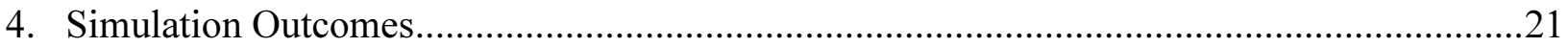

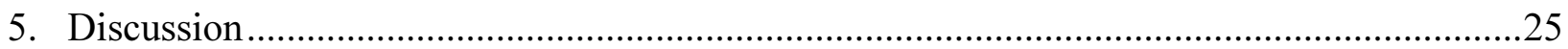

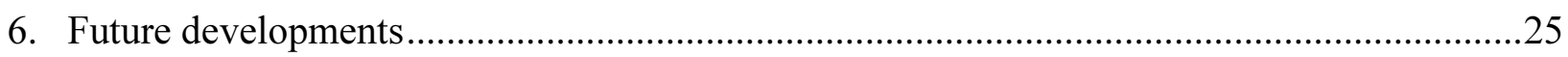

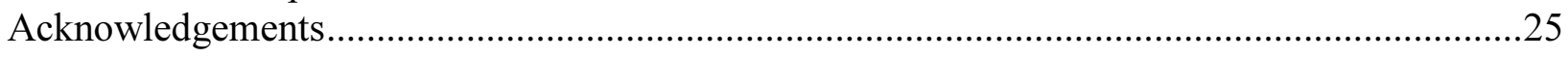

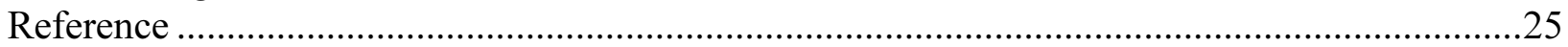




\section{List of Figures}

Figure 1. Operational constraints on hourly power variation, i.e. the unit component power output cannot vary faster than the maximum sustained power rate of variation...................... 9 Figure 2. Representation of the Power Generation Cost (\$) as function of the power level

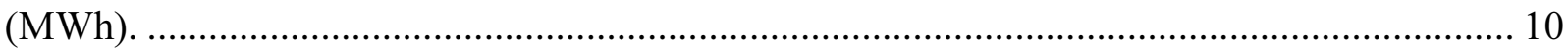

Figure 3. Graphical interface of the EM Dymola model................................................. 12

Figure 4. Evolution of the state variables during ES operation, (a) Power Output (MWh), (b)

Stored Energy (MWh). ....................................................................................... 15

Figure 5. Power generation cost profiles. .................................................................... 16

Figure 6. Price adjustment based on ACE measured imbalance providing penalties to be

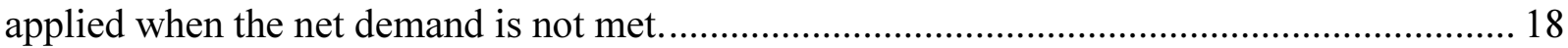

Figure 7. ES discharge mode scenarios. .......................................................................... 20

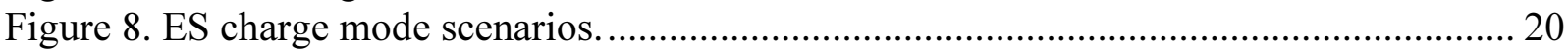

Figure 9. Profit achieved by the N-R HES unit $(\$)$....................................................... 22

Figure 10. Electrical power $(\mathrm{MWh})$. The dashed red line represents the net demand, the solid blue line represents the overall unit power output.......................................................... 22 Figure 11. SES power output (MWh). The solid red line represents the instantaneous power output, the dashed blue lines represent the power operational bounds................................. 23 Figure 12. BOP power output (MWh). The solid red line represents the instantaneous power output, the dashed blue lines represent the power operational bounds.................................. 23 Figure 13. ES power output (MWh). The solid red line represents the instantaneous power output, the dashed blue lines represent the power operational bounds................................. 23 Figure 14. ES stored energy level (MWh). The solid red line represents the instantaneous value, the dashed blue lines represent the bounds for the ES storing capacity...................... 24 Figure 15. ES operation mode (-). The solid red line represents the instantaneous mode, the dashed blue lines represent the modes the ES can be operated (charge or discharge)............ 24 Figure 16. Hydrogen production level $(\mathrm{kg})$....................................................................... 24 


\section{List of Tables}

Table 1. Yearly average Henry Hub gas costs [2] ............................................................... 13

Table 2. Main features of the considered NHES unit components...................................... 17 


\section{Introduction}

The general problem addressed in the Nuclear-Renewable Hybrid Energy System (N-R HES) project is finding the optimum economical dispatch (ED) and capacity planning solutions for the hybrid energy systems [1]. In the present test-problem configuration, the N-R HES unit is composed of three electrical power-generating components, i.e. the Balance of Plant (BOP), the Secondary Energy Source (SES), and the Energy Storage (ES). In addition, there is an Industrial Process (IP), which is devoted to hydrogen generation. At this preliminary stage of identifying optimal economic dispatch and capacity planning solutions, the goal is to find the power outputs of each one of the N-R HES unit components (BOP, SES, ES) and the IP hydrogen production level that maximizes the unit profit by simultaneously satisfying individual component operational constraints.

The optimization problem is solved in the Risk Analysis Virtual Environment (RAVEN) framework. The dynamic response of the N-R HES unit components is simulated by using dedicated object-oriented models written in the Modelica modeling language [2]. This code coupling provides for very accurate predictions since the operational transients imposed by the optimization algorithm are simulated using a control-oriented modeling tool that includes detailed and comprehensive representation of the underlying dynamics of the different unit components. From this standpoint, the ensuing optimization problem is characterized by a very large number of solution variables. To ease the computational burden and to improve the path to a converged solution, a method to better estimate the initial guess for the solution to the optimization problem was developed.

The proposed approach led to the definition of a suitable Monte Carlo-based optimization algorithm (called the preconditioner), which provides an initial guess for the optimal N-R HES power dispatch and the optimal installed capacity for each one of the unit components. The preconditioner provides for a global sampling of the possible solution space and better insures that an initial guess is found that is in the neighborhood of the actual solution. Further, several approximations that provide for representation of component physical dynamics without the need of explicitly modeling their dynamics by means of a set of ordinary differential equations are introduced. In particular, the characteristic dynamics are represented through suitable ramp constraints, which considerably simplify the numerical solving.

In the present report, in order to test the capabilities of the proposed approach, the dispatch problem only is tackled, i.e. a reference unit configuration is assumed, and each one of the N-R HES unit components is assumed to have a fixed installed capacity. At the moment, in order to be consistent with the approach of others on the project, the optimal configuration is the one that maximizes the unit profit. In any case, the cost function can be easily modified to represent the total electricity and hydrogen production costs.

In summary then, the proposed approach allows for accelerated convergence by obtaining an improved initial guess for the solution. The guess is obtained by

- performing the cost function optimization. The N-R HES unit components dynamic response is represented by adopting the corresponding ramp rates, and the flexible operation capabilities are described by imposing the corresponding operational bounds.

- scanning the entire space for solutions, to quickly understand the broad features of the problem, and can also be used to obtain initial conditions for RAVEN. 


\section{NHES unit parameters to be adopted into the Optimization Algorithm}

The estimate for the initial guess to the optimal solution is obtained by including a simplified representation of the individual component dynamics. The dynamic response of a component will in practice be constrained by the component's control system so as not to violate rates of change imposed by service life considerations. So a good approximation to the resulting component response is a maximum linear ramp rate. Such a representation considerably simplifies the numerical calculation and is therefore of considerable value in estimating an improved initial guess solution. In addition, the bounds of the operational range, which represent the component flexible operation capabilities, are accounted for as well. This section describes the appropriate linear ramp constraints and the operational bounds for each of the components in the test problem.

\subsection{General features}

Each component is characterized by the corresponding power operational range. In particular, the electrical power dispatched by every component $(P(i, t))$ is defined as

$$
P(i, t)=\text { Capacity }(i) \cdot x(i, t)
$$

where $x(i, t)$ is the normalized power level of the component $(i)$ at time $(t)$, and Capacity $(i)$ is the installed capacity of the component $(i)\left(M W_{e l} \cdot h\right)$. The instantaneous component power output is always comprised within a lower and an upper bound, as shown in Eq. (2).

$$
P(i, t) \in[P M I N(i) ; P M A X(i)]
$$

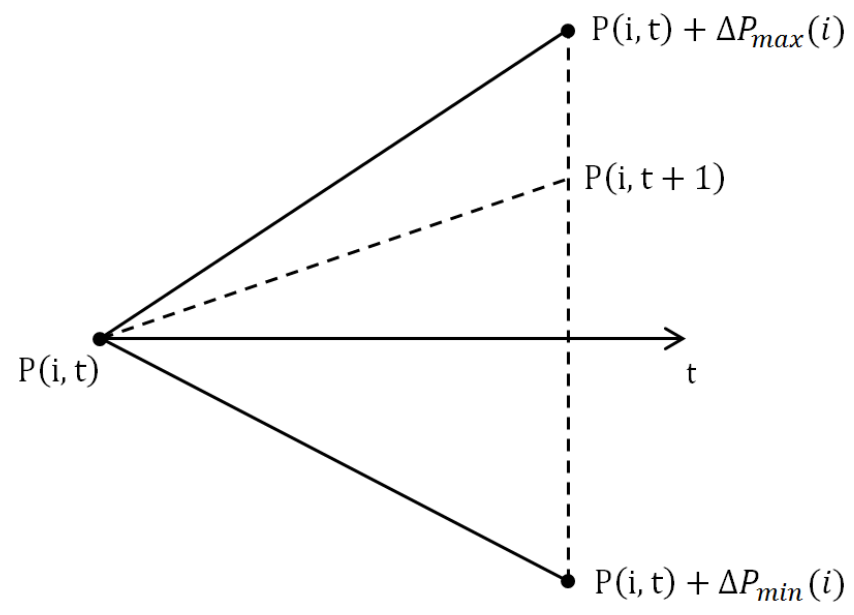

Figure 1. Operational constraints on hourly power variation, i.e. the unit component power output cannot vary faster than the maximum sustained power rate of variation.

Similarly, each component is characterized by a maximum sustained power rate of variation (Figure 1). In particular, $\Delta P_{\min }(i)$ represents the maximum power drop $\left(M W_{e l} \cdot h\right)$ which can be achieved in one hour by the component $(i), \Delta P_{\max }(i)$ represents the maximum power increase $\left(M W_{e l} \cdot h\right)$ which can be achieved in one hour by the component $(i)$.

$$
\text { Power increase } \rightarrow P(i, t+1) \in\left[P(i, t) ; P(i, t)+\Delta P_{\max }(i)\right]
$$




$$
\text { Power drop } \rightarrow P(i, t+1) \in\left[P(i, t)+\Delta P_{\min }(i) ; P(i, t)\right]
$$

As for the evaluation of the power generation cost for each one of the unit components $(C P G(i, t))$, the following functional dependence is assumed (Figure 2):

$$
C P G(i, t)=N L C(i)+[P(i, t)-P M I N(i)] \cdot M C(i)
$$

where $N L C(i)$ is the No-Load Cost for the component $(i)(\$), P(i, t)$ is the power output from the component $(i)$ at time $(t)\left(M W_{e l} \cdot h\right), P M I N(i)$ is the minimum power level for the component $(i)$ $\left(M W_{e l} \cdot h\right), M C(i)$ is the power generation marginal cost for the component $(i)\left(\$ / M W_{e l} \cdot h\right)$.

In Eq. (6), the expression of the No-Load Cost for the component $(i)$ is provided. It represents the operational costs associated to the operation of the component to sustain the minimum electrical power output when the component is committed.

$$
N L C(i)=P M I N(i) \cdot M C(i)+f i x e d O \& M(i)
$$

where fixedO\&M(i) represents the fixed Operation and Maintenance (O\&M) cost for the component (i) (\$).

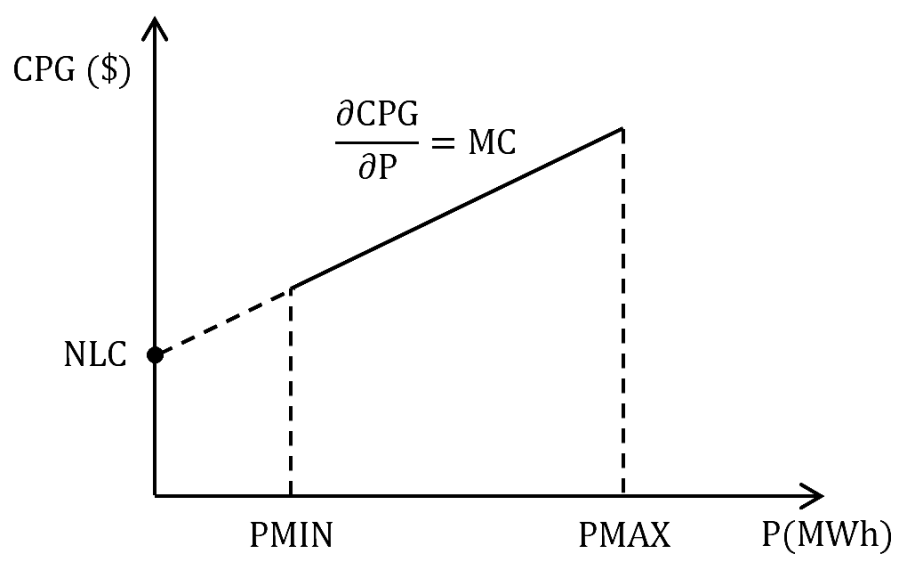

Figure 2. Representation of the Power Generation Cost (\$) as function of the power level (MWh).

\subsection{Industrial Process}

In the present configuration of the N-R HES unit, the integrated IP is represented by high-temperature steam electrolysis (HTSE). HTSE utilizes a combination of thermal energy and electricity to split water into hydrogen and oxygen in SOECs, which can be seen in simple terms as the reverse operation of solid oxide fuel cells (SOECs) [1]. From this standpoint, a portion of the steam produced by the Primary Heat System (PHS) can be diverted from the BOP and disposed to the IP through the Energy Manifold (EM). It represents the thermal energy needed to convert the feed water to low-temperature steam and heat the sweep gas (air). The steam conditions are typical of Light Water Reactor (LWR) technology with a temperature of $318^{\circ} \mathrm{C}$ and a pressure of $5.8 \mathrm{MPa}$. On the other hand, the HTSE process requires both the cathode and anode streams to be heated to $850^{\circ} \mathrm{C}$, which necessitates additional topping heat from an auxiliary heat source. This heat source could come from a combustor, electric heating, or waste heat from a neighboring process. In this assessment, it is assumed that topping heat is provided by electric heating. Therefore, the electricity used by the HTSE plant is apportioned between the electric heaters (to adjust the steam conditions) and the SOEC stacks for electrolysis. 
As for the nominal operating conditions (Eq.(7)), the HTSE process uses a $51.1452 M W_{e l}$ electrical load input, and a $18.4794 \mathrm{MW}$ th thermal energy input to produce $0.401461 \mathrm{~kg} / \mathrm{s}$ of hydrogen.

$$
\text { 18.4794 MW } W_{t h}+51.1452 M W_{e l} \rightarrow 0.401461 \mathrm{~kg} / \mathrm{s}
$$

The corresponding conversion parameter which relates the electric power with the thermal consumption $\left(I P_{t h 2 e l}\right)$ is derived in Eq.(8).

$$
I P_{t h 2 e l}=\frac{51.1452 M W_{e l}}{18.4794 M W_{t h}}=2.77 \frac{M W_{e l}}{M W_{t h}}
$$

As for the hydrogen production rate, the conversion parameter $\left(I P_{t h 2 k g}\right)$, which relates the amount of produced hydrogen with the thermal power consumption, is derived in Eq. (9).

$$
I P_{t h 2 \mathrm{~kg}}=\frac{0.401461 \mathrm{~kg} / \mathrm{s} \cdot 3600 \mathrm{~s} / \mathrm{h} \cdot 1 \mathrm{~h}}{18.4794 \mathrm{MW} W_{t h} \cdot 1 \mathrm{~h}}=78.21 \frac{\mathrm{kg}}{M W_{t h} \cdot h}
$$

Accordingly, by assuming a thermal-to-electrical conversion efficiency equal to $31.8 \%$, the conversion parameter $\left(I P_{k g 2 e l}\right)$, which relates the amount of produced hydrogen with the diverted steam corresponding to a certain lost electrical power output, can be derived.

$$
\begin{aligned}
& 1.0 \mathrm{MW}_{\mathrm{th}} \cdot \mathrm{h}+2.77 \mathrm{MW}_{e l} \cdot \mathrm{h} \rightarrow 78.21 \mathrm{~kg}
\end{aligned}
$$

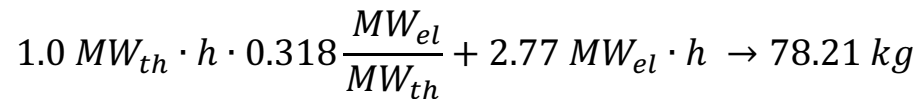

$$
\begin{aligned}
& 0.318 \mathrm{MW}_{e l} \cdot \mathrm{h}+2.77 \mathrm{MW}_{e l} \cdot \mathrm{h} \rightarrow 78.21 \mathrm{~kg} \\
& I P_{k g 2 e l}=\frac{78.21 \mathrm{~kg}}{3.088 \mathrm{MW} W_{e l} \cdot \mathrm{h}}=25.327 \frac{\mathrm{kg}}{\mathrm{MW} W_{e l} \cdot \mathrm{h}}
\end{aligned}
$$

The IP installed capacity is assumed to be fixed. The IP thermal $\left(P_{t h}(I P)\right)$ and electrical power $\left(P_{e l}(I P)\right)$ consumptions at steady-state conditions are equal to

$$
\begin{aligned}
& P_{t h}(I P)=18.4794 M W_{t h} \\
& P_{e l}(I P)=51.1452 M W_{e l}
\end{aligned}
$$

From these values, the overall IP power consumption expressed in terms of electrical power can be easily derived (Eq. (15)).

$$
\begin{aligned}
P(I P) & =P_{t h}(I P) \cdot \eta+P_{e l}(I P) \\
& =18.4794 M W_{t h} \cdot 0.318 \frac{M W_{e l}}{M W_{t h}}+51.1452 M W_{e l}= \\
& =57.02 M W_{e l}
\end{aligned}
$$

The maximum fraction of steam flow rate that can be diverted from the BOP and that can be effectively used to produce hydrogen is limited by an upper bound. Accordingly, when the BOP is operated at very low power levels, the IP cannot use the entire amount of diverted steam. In particular, though the unused electric power production capabilities $(P M A X(B O P)-P(B O P, t))$ might assume very high values, the largest amount of electric power which can be sacrificed to operate the IP is equal to $57.02 \mathrm{MW}_{e l}$. Therefore, the instantaneous amount of produced hydrogen $\left(\mathrm{H}_{2}(t)\right)$ is equal to 


$$
H_{2}(t)=\min (P M A X(B O P)-P(B O P, t), P(I P)) \cdot I P_{k g 2 e l}
$$

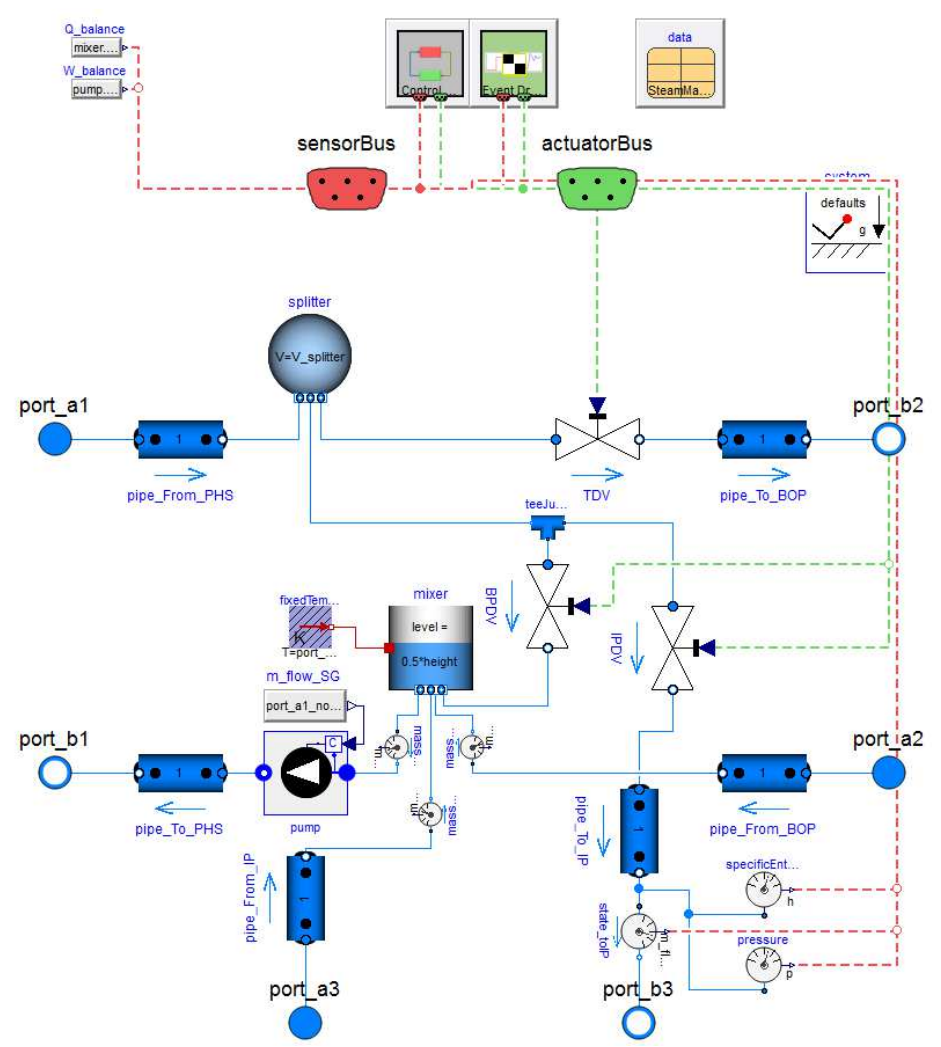

Figure 3. Graphical interface of the EM Dymola model.

In Figure 3, the graphical interface of the EM Dymola model is represented. The PHS-produced steam flow rate is collected into a volume (splitter), and then it is subdivided in two ways. The former leads to the BOP, and it is expected to produce electrical power $(P(B O P, t))$. The steam flow rate is adjusted by regulating a dedicated valve ( $T D V$ valve). The latter is further subdivided in two ways, i.e. one leading to the IP (via the IPDV valve), and another one directly leading to the mixer (via the $B P D V$ valve), where the steam is condensed to be sent to the PHS. Therefore, when the BOP power level is particularly low and the IP cannot use all the available steam to produce hydrogen, the leftover steam flow rate is disposed through the $B P D V$ valve to the mixer.

\subsection{Secondary Energy Source}

The SES is a Combustion turbine (CT). Its installed capacity is equal to $35 \mathrm{MW} W_{e l} \cdot h$. As for the SES flexible operation capabilities, the $\mathrm{CT}$ is a component conceived and designed to be operated as a peaking unit. Therefore, it is characterized by a high operating flexibility:

$$
\begin{aligned}
& x_{\min }(S E S)=0.375, x_{\max }(S E S)=1.0 \\
& \Delta P_{\min }(S E S)=-29.0 \mathrm{MW}_{e l} \cdot h, \Delta P_{\max }(S E S)=+15.0 \mathrm{MW} W_{e l} \cdot h
\end{aligned}
$$

The marginal cost for power generation for a gas turbine can be derived by summing the variable O\&M costs (var $O \& M)$ and the fuel consumption cost. The recommended value for the variable O\&M costs is $4.27 \$ / M W_{e l} \cdot h$ [4]. The fuel consumption cost represents the cost associated to the natural gas consumption to produce $1 \mathrm{MW}$ el $\cdot h$. This parameter can be derived by multiplying the gas price by the 
CT heat rate. In [4], the range for the gas price, measured in \$/MMBtu (US dollars per million BTUs), is discussed. In particular, the Henry Hub gas price in recent times has encompassed values ranging from approximately $2 \$ / M M B t u$ to $4 \$ / M M B t u$. In Table 1 , the average Henry Hub gas costs for 2014, 2015, 2016 and 2017 (YTD) are reported.

Table 1. Yearly average Henry Hub gas costs [4].

\begin{tabular}{ccccc}
\hline & $\$$ MMBtu (2014) & \$/MMBtu (2015) & \$MMBtu (2016) & \$/MMBtu (2017-YTD) \\
\hline Henry Hub & 4.11 & 2.61 & 2.50 & 3.25 \\
\hline
\end{tabular}

The heat rate is a common measure of the thermal efficiency of a power plant. It is defined as the energy input to a system (Btu) divided by the electricity generated $\left(k W_{e l} \cdot h\right)$. According to [4], the "conventional" CT plants have a heat rate equal to $10850 \mathrm{Btu} / \mathrm{kW}$ el $\cdot h$. Therefore, the SES marginal cost will be equal to

$$
\begin{aligned}
M C(S E S) & =\operatorname{var} \text { O\&M+HeatRate }(\text { SES }) \cdot\langle\text { GasPrice }\rangle= \\
& =4.27 \frac{\$}{M W_{e l} \cdot h}+10850 \frac{B t u}{k W_{e l} \cdot h} \cdot 3.12 \frac{\$}{M M B t u}=38.12 \frac{\$}{M W_{e l} \cdot h}
\end{aligned}
$$

As for the SES No-Load cost definition, the recommended value of the fixed O\&M is comprised between $5.2 \mathrm{M} \$ / y$ and $10.1 \mathrm{M} \$ / y$ [4]. Therefore, by assuming a reference value equal to $7.0 \mathrm{M} \$ / y$, the $N L C(S E S)$ can be derived (Eq. (20)).

$$
\begin{aligned}
N L C(S E S) & =\operatorname{PMIN}(S E S) \cdot M C(S E S)+\text { fixedO\&M }(S E S)= \\
& =0.375 \cdot 35 M W_{e l} \cdot h \cdot 38.12 \frac{\$}{M W_{e l} \cdot h}+\frac{7 \cdot 10^{6} \$ / y}{8760 \mathrm{~h} / y}=1299.44 \$
\end{aligned}
$$

\subsection{Balance of Plant}

The BOP installed capacity is equal to $300 \mathrm{MW} e l \cdot h$. As for the BOP flexible operation capabilities, the steam turbine is a component conceived and designed to be mostly operated at rated power conditions. Therefore, it is characterized by a limited operational range:

$$
x_{\min }(B O P)=0.465, x_{\max }(B O P)=1.0
$$

Similarly, the corresponding ramp-rates are limited.

$$
\Delta P_{\min }(B O P)=-55 \mathrm{MW} \text { el } \cdot h, \Delta P_{\max }(B O P)=+55 \mathrm{MW} W_{e l} \cdot h
$$

As for the evaluation of the BOP marginal costs, the O\&M costs of the conventional part of nuclear plants cannot be found as a separate cost with respect to the nuclear reactor. Therefore, under the assumption of a direct proportionality between capital and O\&M costs, O\&M costs can be estimated as $26.3 \%$ of the reactor O\&M cost [4]. For a nuclear reactor, the variable costs include only some maintenance material and supplies and expenses, but in a smaller quantity than the same contributions as fixed costs. From this standpoint, the recommended value for the reactor marginal cost is equal to $0.50 \$ / M W_{e l} \cdot h[5]$.

$$
M C(B O P)=M C(\text { reactor }) \cdot 0.263=0.132 \frac{\$}{M W_{e l} \cdot h}
$$


This value would be valid whether all the steam produced by the nuclear reactor was disposed to the BOP steam turbine. On the other hand, in the present configuration of the N-R HES unit, the steam flow rate can either be disposed to the BOP steam turbine or it can be diverted to the IP, by providing the HTSE with the needed thermal energy. Since the BOP and the IP share the same steam flow rate, the choice of producing electrical power by operating the BOP causes the hydrogen loss of production. Therefore, the definition of the BOP marginal costs should account for the loss of earnings corresponding to the decision of not providing the HTSE with steam (no hydrogen production). This approach is called Opportunity cost of not-producing by product, i.e. when a decision needs to be made between several mutually exclusive alternatives, the cost of the made choice is equal to the loss of potential gain that would have derived by taking the alternative one.

In Section 2.2, the overall IP power consumption expressed in terms of electrical power $(P(I P)=$ 57.02 $M W_{e l}$ ) was defined (Eq. (15)). Accordingly, the BOP marginal cost definition based on the Opportunity cost of not-producing by product will be applied in the power range $[P M A X(B O P)-$ $P(I P) ; P M A X(B O P)]$. To evaluate the BOP marginal cost according to the proposed approach, first the profit corresponding to the production of $1 \mathrm{~kg}$ of hydrogen needs to be evaluated. Then, the obtained value is related to the electrical power needed to produce it (Eq. (24)).

$$
\begin{aligned}
M C(B O P) & =M C(\text { reactor }) \cdot 0.263+\left[\text { Price }^{H_{2}}-H_{2}(O \& M)\right] \cdot I P_{k g 2 e l}= \\
& =36.91 \frac{\$}{M W_{e l} \cdot h}
\end{aligned}
$$

where Price $\mathrm{H}_{2}$ is the hydrogen price $(1.50 \$ / \mathrm{kg}), \mathrm{H}_{2}(O \& M)$ is the variable Operation and Maintenance cost $\left(4.8 \cdot 10^{-2} \$ / \mathrm{kg}\right)$, and $I P_{k g 2 e l}$ is a conversion coefficient which related the amount of produced hydrogen with the corresponding BOP electrical power consumption $(25.327 \mathrm{~kg} / \mathrm{MW}$ el $\cdot h)$. Hence, the BOP marginal cost is defined as

$$
M C(B O P)= \begin{cases}0.132 \$ / M W_{e l} \cdot h & \text { for } P(B O P)<242.98 M W_{e l} \\ 36.91 \$ / M W_{e l} \cdot h & \text { for } 242.98 M W_{e l} \leq P(B O P) \leq 300.0 M W_{e l}\end{cases}
$$

Accordingly, when $P(B O P, t)$ belongs to the power range $[242.98 \mathrm{MW}$ el $; 300.0 \mathrm{MW}$ el $]$, the corresponding power generation cost $(C P G(B O P, t))$ will be evaluated as follows

$$
\begin{aligned}
C P G(B O P, t)= & N L C(B O P)+\left[242.98 M W_{e l}-P M I N(B O P)\right] \cdot 0.132 \$ / M W_{e l} \cdot h+ \\
& +\left[P(B O P, t)-242.98 \mathrm{MW}_{e l}\right] \cdot 36.91 \$ / M W_{e l} \cdot h
\end{aligned}
$$

As for the evaluation of the BOP No-Load cost, the recommended value of the fixed O\&M cost for the nuclear reactor is equal to $62.5 \mathrm{M} \$ / y$ [5]. By assuming that the fixed O\&M cost for the BOP can be estimated as $26.3 \%$ of the reactor O\&M fixed cost, the $N L C(B O P)$ can be accordingly derived (Eq. (27)).

$$
\begin{aligned}
N L C(B O P) & =P M I N(B O P) \cdot M C(B O P)+\text { fixedO\&M }(B O P)= \\
& =0.465 \cdot 300 M W_{e l} \cdot h \cdot 0.132 \frac{\$}{M W_{e l} \cdot h}+\frac{62.5 \cdot 10^{6} \$ / y \cdot 0.263}{8760 \mathrm{~h} / y}= \\
& =1894.84 \$
\end{aligned}
$$




\subsection{Energy Storage}

The main feature which characterizes the ES is the modularity, i.e. any facility size can be ideally achieved. Actually, the installed capacity is one of the variables to be optimized. In [4], two recentlybuild large scale, grid storage projects in California are mentioned, and some approximate guidance on the relationship between storage and power is provided. "The San Diego Gas and Electric's Escondido storage facility has a capacity of $120 \mathrm{MWh}$ and maximum power of $30 \mathrm{MW}$, while the Tesla's Ontario, California storage facility has a capacity of $80 \mathrm{MWh}$ and maximum power of $20 \mathrm{MW}$ " [4]. In the developed model, the data referred to the first storage facility were adopted. Therefore, as for the installed capacity,

$$
\operatorname{Capacity}(E S)=120 \mathrm{MW} \text { el } \cdot h
$$

As for the flexible operation capabilities, the modeling of the ES is more complicated than the modeling of the other components. In particular, the power operational bounds are expressed in terms of energy storing capabilities, and the electrical power constraints need to be derived accordingly. In particular, the expression reported in Section 2.1 to describe the instantaneous power level (Eq.(1)) needs revision. The maximum power level is derived from the installed capacity and the minimum time to go from full charge to full discharge (4 hours), as shown in Figure 4.

$$
P(i, t)=\left(\frac{\operatorname{Capacity}(i)}{4 h}\right) \cdot x(i, t)
$$

where $x(i, t)$ is the normalized power level of the component $(i)$ at time $(t)$, and Capacity $(i)$ is the installed capacity of the component $(i)\left(M W_{e l} \cdot h\right)$.

Since the ES can go from full charge to full discharge, the upper and the lower bounds assume the following values (Eq.(30)):

$$
x_{\min }(E S)=0.0, x_{\max }(E S)=1.0
$$

As for the ramp-rates, since the battery has no inertia or moving parts, any allowable power transients compatible with the maximum allowable power level $(30.0 \mathrm{MW} e l)$ can be achieved.

$$
\Delta P_{\min }(E S)=-30.0 \mathrm{MW} \text { el }, \Delta P_{\max }(B O P)=+30.0 \mathrm{MW} \text { el }
$$

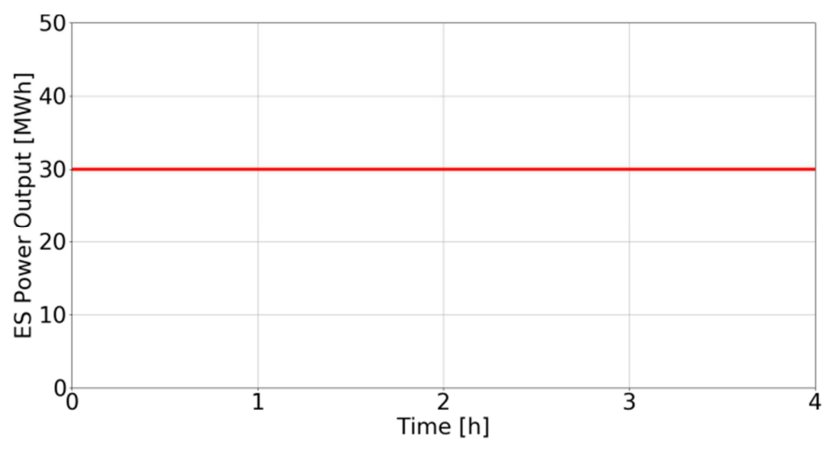

(a)

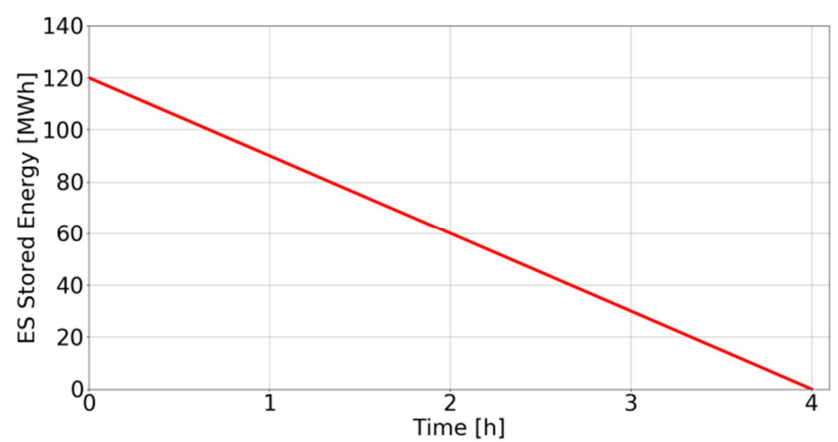

(b)

Figure 4. Evolution of the state variables during ES operation, (a) Power Output (MWh), (b) Stored Energy (MWh). 
As for the ES operation, the adopted strategy is different from the other unit components. In particular, the operation of a conventional generating unit is based on the instantaneous value of the energy price, i.e. the unit is committed and the electrical power is dispatched only if the profit deriving from selling the electricity is higher than the overall power generation costs. This paradigm does not work for the ES facility, since it has the capability of both absorbing and dispatching the electrical power. In particular, the ES operation mode is not ruled by the instantaneous electricity price, but by the difference between the future and the instantaneous electricity price. Therefore, the forecast of the electricity prices are necessary to operate the ES facility. For instance, let us evaluate the ES operation mode, when the combined power output of the BOP and the SES is lower than the net demand. In that case, the operator is not forced to dispatch the electrical power stored in the ES facility. In particular, if the electricity price is expected to rise during the hours following, it might be more profitable to pay the penalty associated to the lost load at the moment and to dispatch the electrical power afterwards. It follows that the commitment strategy is evaluated according to the comparison between the instantaneous profit and the future profit based on the short-term electricity price forecast.

Generally speaking, the ES facility is expected to supply its power contribution as the last resource. In particular, if the BOP and the SES power outputs cannot meet the net demand, the ES provides its contribution according to its capabilities. Similarly, when the net demand assumes very low values, the BOP and the SES tries to reduce their power outputs as much as they can. If, despite these efforts, the unit is still overproducing, then the ES absorbs the surplus according to its storing capabilities. This strategy should derive from the economic optimization of the ES operation, which is based on the above-mentioned paradigm. Unfortunately, in the present configuration of the algorithm, the optimization is achieved by maximizing the cost function hour by hour, i.e. the optimization of the power dispatch is based on the instantaneous values of the net demand and the electricity price. This hierarchy in the power dispatch can be mimicked by adopting for the ES a higher marginal cost than the other unit components, though the variable O\&M costs for the ES facility are very low.

$$
M C(E S)=140.0 \$ / M W_{e l}
$$

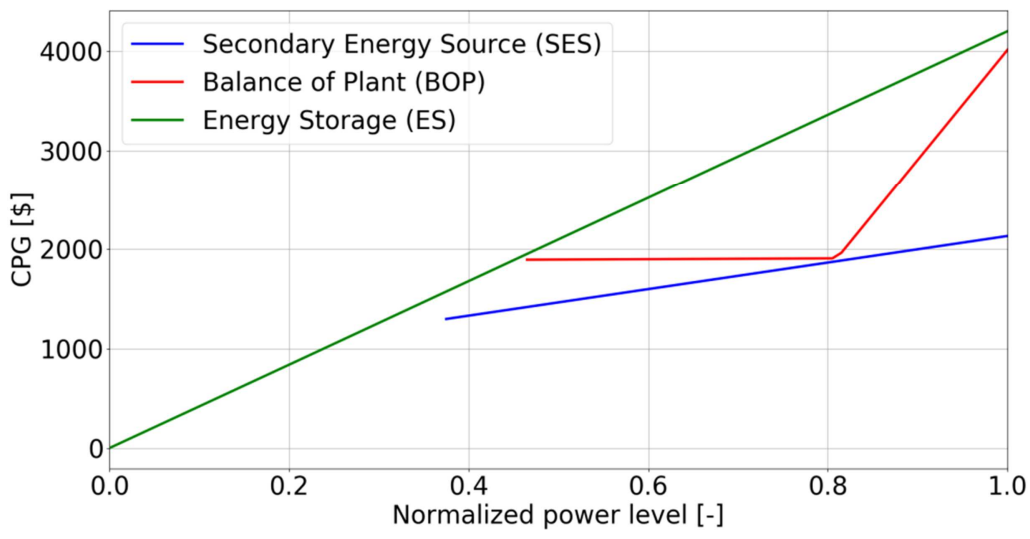

Figure 5. Power generation cost profiles.

In Figure 5, the profiles of the power generation costs $(C P G)$ as function of the normalized power level for the SES, the BOP and the ES are represented. In particular, the $C P G(B O P)$ profile is characterized by a steep variation, due to the definition of the BOP marginal cost based on the Opportunity cost of not-producing by product. As for the $C P G(E S)$ profile, the value of the marginal cost was purposefully tuned so that ES is always the last components to be committed. By setting this artificial value, the 
expected hierarchy in the power dispatch is satisfied. In Table 2, the unit data adopted in the optimization algorithm are reported.

Table 2. Main features of the considered NHES unit components.

\begin{tabular}{cccccccc}
\hline Item & Capacity (MWh) & $\mathbf{x}_{\max }(-)$ & $\mathbf{x}_{\min }(-)$ & $\Delta \mathbf{P}_{\max } \uparrow(\mathbf{M W h})$ & $\Delta \mathbf{P}_{\max } \downarrow$ (MWh) & $\mathbf{N L C}(\mathbf{S})$ & $\mathbf{M C}(\mathbf{S} / \mathbf{M W h})$ \\
\hline SES & 35.0 & 1.0 & 0.375 & +15.0 & -29.0 & 1299.44 & 38.12 \\
BOP & 300.0 & 1.0 & 0.465 & +55.0 & -55.0 & 1894.84 & $0.132 / 36.91$ \\
ES & 30.0 & 1.0 & 0.0 & +30.0 & -30.0 & 0.0 & 40.0 \\
\hline
\end{tabular}

\section{Monte Carlo sampling}

The algorithm developed for improving the initial guess is described here for the case of N-R HES unit electrical power generation and the hydrogen production that maximize the profit of the unit. The optimization algorithm is based on the implementation of a Monte Carlo approach, i.e. a set of stochastic power scenarios is sampled for each one of the N-R HES unit components. For each scenario, the corresponding value of a suitably defined cost function is evaluated. After having simulated a sufficient number of power histories, the configuration which ensures the highest profit is selected as the optimal one.

\subsection{Cost function definition}

The variables to be optimized are the instantaneous power outputs of the N-R HES unit components, i.e. $P(B O P, t), P(S E S, t)$ and $P(E S, t)$, and the instantaneous hydrogen production $\left(H_{2}(t)\right)$. As shown in Eq. (33), the cost function represents the N-R HES unit profit (profit $(t)$ ), and it is defined as the summation of several contributions. In particular, a suitable index to account the different time frames is defined, i.e. the first summation is carried out from 1 to $N$, where $N$ can be equal to 1 (the optimal solution is selected hour by hour), 24 (the optimization time horizon is equal to the entire day) or 168 (the optimization time horizon is equal to the entire week). In the present configuration of the algorithm, the optimal scenario is obtained by maximizing the cost function hour by hour (i.e. $N=1$ ). However, such an approach can be improved since more favorable configurations might be found whether the N-R HES unit components operation was optimized over longer time horizons, i.e. over a day or over a week. An additional index to account the different N-R HES unit components is defined, i.e. $M=1,2,3,4$ is referred to SES, BOP, ES, IP, respectively.

$$
\begin{aligned}
\max \{\operatorname{profit}(t)\} & =\max \left\{\sum _ { t = 1 } ^ { N } \left[\left(\sum_{i=1}^{M-1} P(i, t)\right) \cdot \operatorname{Price}^{E L}+H_{2}(t) \cdot \operatorname{Price}^{H_{2}}+\sum_{i=1}^{M-1} C P G(i, t)+\right.\right. \\
& \left.\left.-\operatorname{VOLL}(t) \cdot\left|\operatorname{Net} D(t)-\sum_{i=1}^{M-1} P(i, t)\right|\right]-\sum_{i=1}^{M} F C(i)\right\}
\end{aligned}
$$

where $P(i, t)$ is the electrical power output of component $(i)$ at time $(t)\left(M W_{e l} \cdot h\right)$, Price ${ }^{E L}$ is the electricity price $\left(\$ / M W_{e l} \cdot h\right), H_{2}(t)$ is the amount of hydrogen produced at time $(t)(\mathrm{kg})$, Price $^{H_{2}}$ is the hydrogen price $(\$ / \mathrm{kg}), C P G(i, t)$ is the power generation cost for unit $(i)$ at time $(t)(\$), \operatorname{VOLL}(t)$ is the Value Of the Lost Load $\left(\$ / M W_{e l} \cdot h\right), \operatorname{Net} D(t)$ is the instantaneous value of the net demand at time $(t)\left(M W_{e l} \cdot h\right), F C(i)$ is the fixed cost for the component $(i)(\$)$. 


\subsection{Power imbalance penalty}

In the present version of the optimization algorithm, the operational reserves are not represented. In addition, the studied time-scale is such that the frequency regulation process is not accounted for. Accordingly, the only penalty in the cost function is the one which represents the instantaneous imbalance between the net demand $(\operatorname{Net} D(t))$ and the overall unit electric power production $\left(\sum_{i=1}^{M-1} P(i, t)\right)$, i.e. the N-R HES unit is expected to pay a fee whether the overall power production either does not meet or exceeds the net demand. This additional contribution in the cost function provides the drivers for response to tie the grid power imbalances.

The penalty is determined by multiplying the penalty factor, which is represented by the Value of the Load Load (VOLL(t)), by the instantaneous energy imbalance. According to [5], the penalty coefficient is derived from the price adjustment curve based on hyperbolic sine functions with different multipliers (Figure 6).

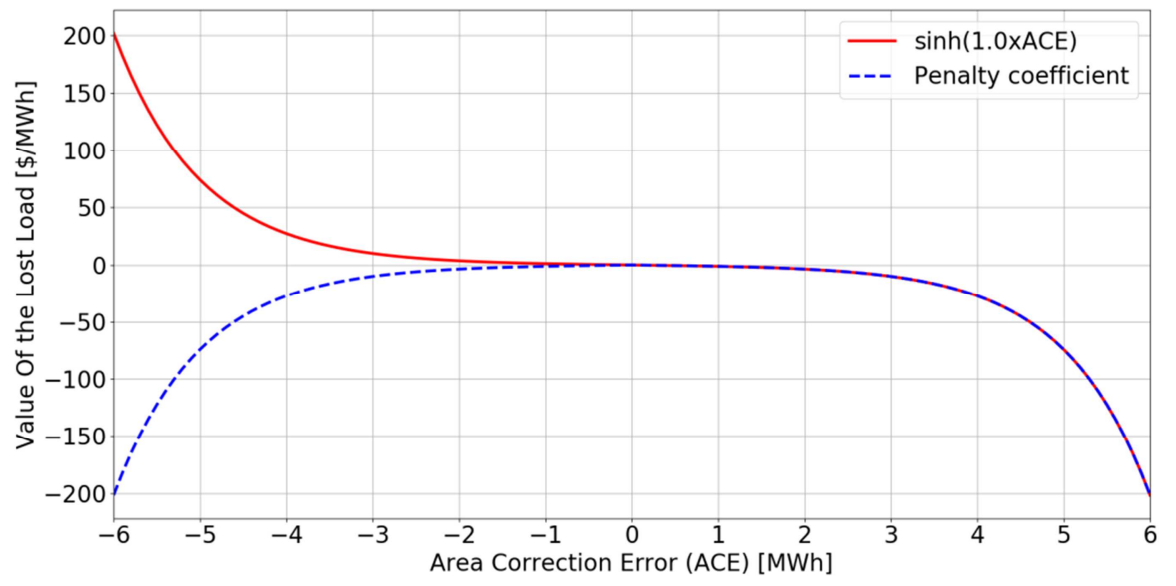

Figure 6. Price adjustment based on ACE measured imbalance providing penalties to be applied when the net demand is not met.

A multiplier can be chosen as a large number to be more punitive. The ACE (Area Correction Error), which represents the real time measurement of the difference between the net demand and the overall unit electrical power production, is sampled every 5 minutes [5]. This parameter represents the input of the price adjustment curve. Since the currently adopted model is characterized by an hourly time resolution, the power imbalance is assumed to be uniform over the simulated hour. Therefore, the value of the ACE will be equal to one-twelfth of the sampled power imbalance. In Eq. (34), the mathematical expression of the $\operatorname{VOLL}(\mathrm{t})\left(\$ / M W_{e l} \cdot h\right)$ is provided.

$$
\operatorname{VOLL}(t)=\sinh \left(m \cdot\left|N e t D(t)-\sum_{i=1}^{M-1} P(i, t)\right| / 12\right)
$$

\subsection{Sampling procedure}

The proposed Monte Carlo approach is based on the hourly sampling of the N-R HES unit components power outputs. The sampling procedure works as follows: 


\subsubsection{Sampling the BOP and the SES instantaneous power outputs}

For every scenario, the SES and the BOP are assumed either to increase $\left(U P_{\text {inds }}\right)$ or to reduce $\left(D O W N_{\text {inds }}\right)$ their electrical power outputs. The selection of the components ramping up/down is performed by sampling random numbers $(u(t) \sim U[-1.0,1.0])$.

$$
\begin{aligned}
& U P_{\text {inds }}=u(t) \geq 0.0 \\
& D O W N_{\text {inds }}=u(t)<0.0
\end{aligned}
$$

The dispatched electrical power outputs are evaluated starting from the power outputs at the previous time step $(P(i, t-1))$. This approach ensures the modeled power production process to be a system with memory, i.e. the instantaneous power level is affected by the value assumed at the previous timestep.

The BOP and the SES power variations are evaluated by sampling a value which is lower than the maximum sustainable power variation $(\Delta P \max (i))$. In this way, the operational constraints are inherently met, i.e. the sampled power profiles do not violate the limits imposed by the characteristic ramp-rate constraints.

$$
\begin{aligned}
& \Delta P(i, t)=u(t) \cdot \Delta P \max (i) \\
& P\left(U P_{\text {inds }}, t\right)=P\left(U P_{\text {inds }}, t-1\right)+\Delta P\left(U P_{\text {inds }}, t\right) \\
& P\left(D O W N_{\text {inds }}, t\right)=P\left(D O W N_{\text {inds }}, t-1\right)-\Delta P\left(D O W N_{\text {inds }}, t\right)
\end{aligned}
$$

\subsubsection{Definition of the ES operation mode and ES power output sampling}

The sum of the sampled power outputs needs to satisfy a specific constraint. In particular, the sum of the power outputs produced by all the components is expected to be equal to the net demand, i.e. the load demand minus solar and wind power contributions.

$$
\sum_{i=1}^{M-1} P(i, t)=N e t D(t)
$$

The comparison of the sum of the sampled power outputs $(P(S E S, t)$ and $P(B O P, t))$ with the instantaneous value of the net demand $(N e t D(t))$ allows defining the ES operation mode, i.e. "charge" or "discharge".

If $N e t D(t)-P(B O P, t)-P(S E S, t) \geq 0$, then the overall electrical power production is not sufficient to meet the net demand, and the ES contribution is necessary. Therefore, the ES is in "discharge mode", and it provides the needed electrical power, according to the available stored energy and the flexible operation capabilities. Once evaluated the ES operation mode, the ES electrical power output needs to be estimated by considering the amount of stored energy. There are two possibilities:

a) The power imbalance integrated over the simulated hour $([\operatorname{Net} D(t)-P(B O P, t)-P(S E S, t)]$. $1 h)$ is lower than the available stored energy $\left(E S(t-1)-E S^{m i n}\right)$, as shown in Figure $7 \mathrm{a}$. The ES produces all the electrical power needed to restore the energy balance.

b) The power imbalance integrated over the simulated hour is larger than the stored energy, as shown in Figure $7 \mathrm{~b}$. The ES produces as much electrical power as it can, compatibly with the operational 
limits $\left(E S^{\mathrm{min}}\right)$, to reduce the energy imbalance. Since the net demand cannot be met by the N-R HES unit components, the corresponding penalty is expected to be paid.

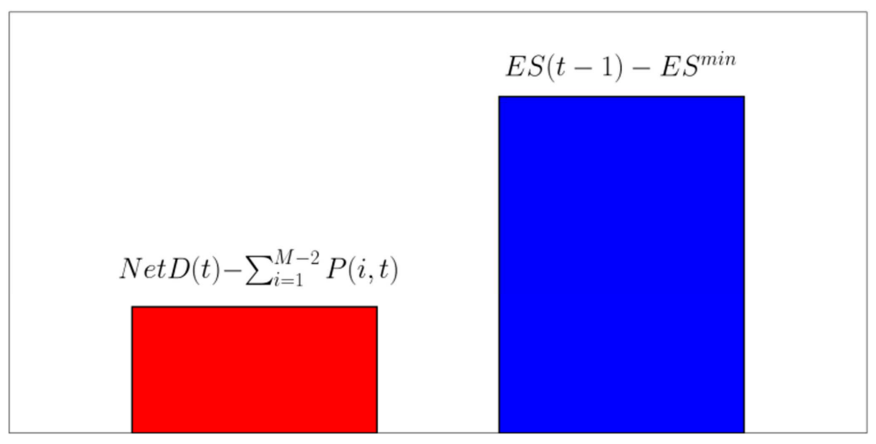

(a)

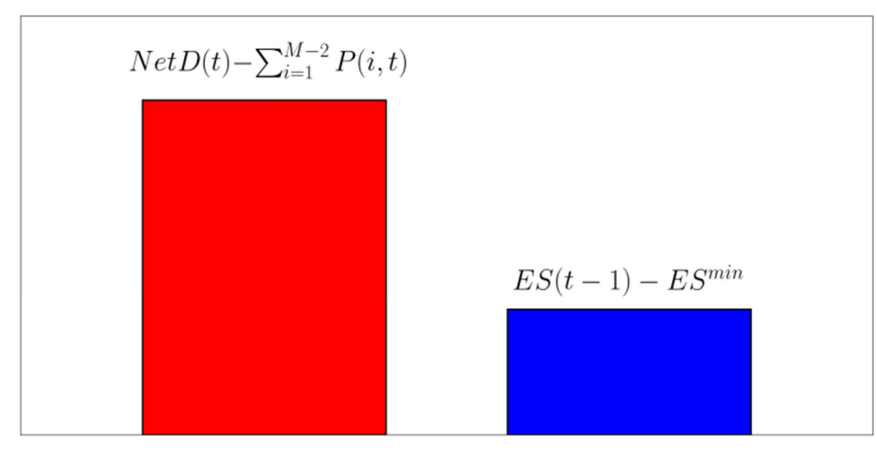

(b)

Figure 7. ES discharge mode scenarios.

On the other hand, if $N e t D(t)-P(B O P, t)-P(S E S, t)<0$, then the sum of the sampled power outputs is larger than the net demand, and the power excess can be stored in the ES, i.e. the ES is in "charge mode". Once evaluated the ES operation mode, the ES electrical power output needs to be estimated by considering the residual energy storing capabilities. There are two possibilities:

a) The power imbalance integrated over the simulated hour $([\operatorname{Net} D(t)-P(B O P, t)-P(S E S, t)]$. $1 h)$ is lower than the residual energy storing capabilities $\left(E S^{\max }-E S(t-1)\right)$, as shown in Figure 8a. The ES can absorb the power excess, and restore the energy balance.

b) The power imbalance integrated over the simulated hour is larger than the residual energy storing capabilities, as shown in Figure 8b. The ES absorbs as much energy as it can, compatibly with the operational limits $\left(E S^{\max }\right)$, to reduce the energy imbalance. Since the net demand cannot be met by the N-R HES unit components, the corresponding penalty is expected to be paid.

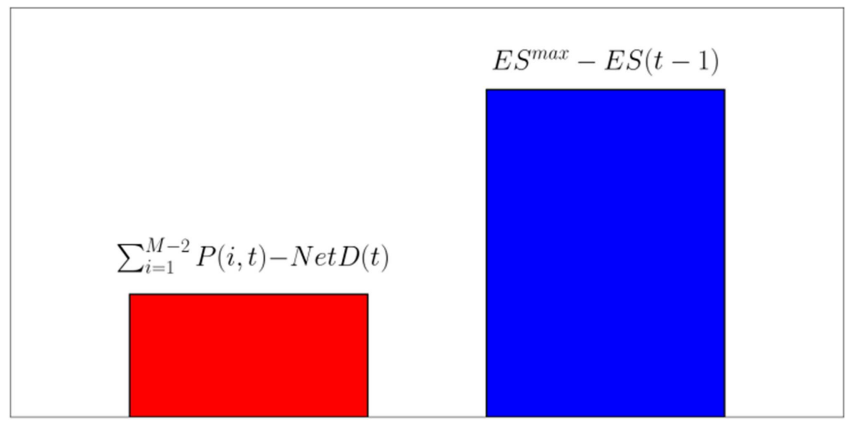

(a)

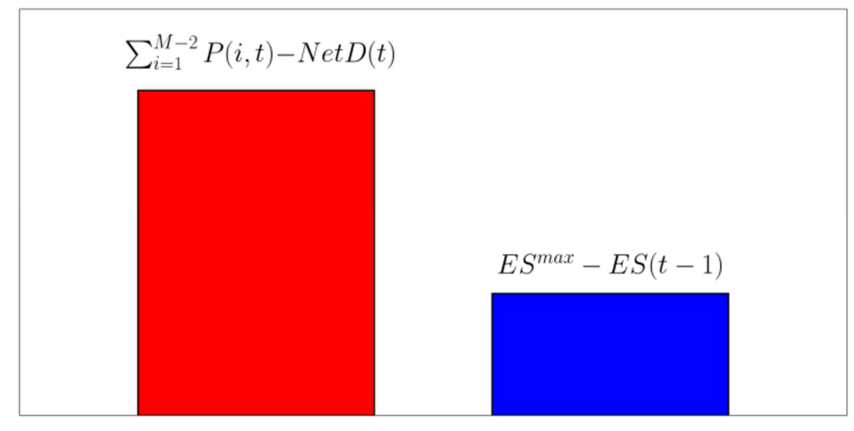

(b)

Figure 8. ES charge mode scenarios.

At the end of the sampling procedure, a saturation effect needs to be imposed to the ES power output. As mentioned in Section 2.5, the ES maximum power output is equal to $30.0 \mathrm{MW}$ el. Therefore, if the absolute value of the sampled ES power output is higher than this physical limit, the value is saturated.

\subsubsection{Iterative constraint verification procedure}

After having sampled the power outputs for all the N-R HES unit components, a while loop is foreseen to adjust the instantaneous power variations of all the components to meet the imposed constraints. First, the instantaneous value of the net demand needs to be balanced by the overall unit power outputs. Therefore, the electrical power produced by each component is normalized accordingly: 


$$
P(i, t)=P(i, t) \cdot\left(\frac{N e t D(t)}{\sum_{i=1}^{M-1} P(i, t)}\right)
$$

This normalization is expected to slightly modify all the sampled values. Therefore, the verification of the operational constraints needs to be checked, i.e. the adjusted values are saturated meet the limitation on the power ramp rates, both on power increases and power drops.

$$
\begin{aligned}
& \Delta P(i, t)=P(i, t)-P(i, t-1) \\
& \Delta P_{\text {UPinds }}=\Delta P(i, t)>\Delta P \max (i) \\
& \Delta P_{\text {DowNinds }}=\Delta P(i, t)<0 \text { and }|\Delta P(i, t)|>\Delta P \max (i) \\
& P\left(\Delta P_{\text {UPinds }}, t\right)=P\left(\Delta P_{\text {UPinds }}, t-1\right)+\Delta P \max \left(\Delta P_{\text {UPinds }}\right) \\
& P\left(\Delta P_{\text {DowNinds }}, t\right)=P\left(\Delta P_{\text {DowNinds }}, t-1\right)-\Delta P \max \left(\Delta P_{\text {DowNinds }}\right)
\end{aligned}
$$

Finally, a last saturation effect is imposed, i.e. the power output of each component cannot be greater/lower than the maximum/minimum operational bounds.

$$
\begin{aligned}
& P_{\text {MAXinds }}=P(i, t)>\operatorname{Capacity}(i) \cdot x_{\max }(i) \\
& P_{\text {MINinds }}=P(i, t)<\operatorname{Capacity}(i) \cdot x_{\min }(i) \\
& P\left(P_{\text {MAXinds }}, t\right)=\operatorname{Capacity}(i) \cdot x_{\max }(i) \\
& P\left(P_{\text {MINinds }}, t\right)=\operatorname{Capacity}(i) \cdot x_{\min }(i)
\end{aligned}
$$

Since the induced alteration of the sampled power outputs might have changed the relationship between the overall unit power output and the instantaneous value of the net demand, the above-described procedure to evaluate the ES operating conditions needs to be repeated. The advantage of this iterative procedure is that it allows normalizing each sampled power scenario so that the penalty is not likely to be paid, by ensuring at the same time that the operational constraints are verified.

\subsubsection{Cost function evaluation}

Once the power outputs of the different components are sampled by respecting the corresponding operational constraints, the hydrogen production $\left(H_{2}(t)\right)$ is evaluated (Eq. (16)). At this point, the unit profit can be evaluated. This operation is repeated for all the sampled scenarios, and then they are ranked according to the corresponding profits. Finally, the configuration which maximizes the N-R HES unit profit for the simulated hour $(\max \{\operatorname{profit}(t)\})$ is selected as the optimal one.

\section{Simulation Outcomes}

The performance of the algorithm for improving initial guess estimate is assessed in this section through simulations. A net demand for electricity is provided to the N-R HES unit, and the optimal dispatch of individual components to maximize profit at each hour is calculated while subject to the ramp operating constraints characteristic of each component. The proposed approach for improving the initial guess for the actual full-blown optimization problem is evaluated according to the achievement level of the following objectives:

- the hourly values of the net demand need to be met by the overall unit power production; 
- the limits on the maximum sustained power rate of variation characteristic of each one of the unit components need to be respected;

- the bounds of the operational range of each one of the unit components need to be respected.

In Figure 9, the unit profit of the N-R HES unit is represented. In Figure 10, the net demand profile (dashed red line) and the overall unit power output (solid blue line) are represented. The net demand profile is not always met by the unit power output, i.e. few scenarios where the unit is over-producing or it is under-producing occur. These scenarios are due to the operational limits which characterize the unit components, i.e. the bounds of the operational range and the maximum hourly power variations.

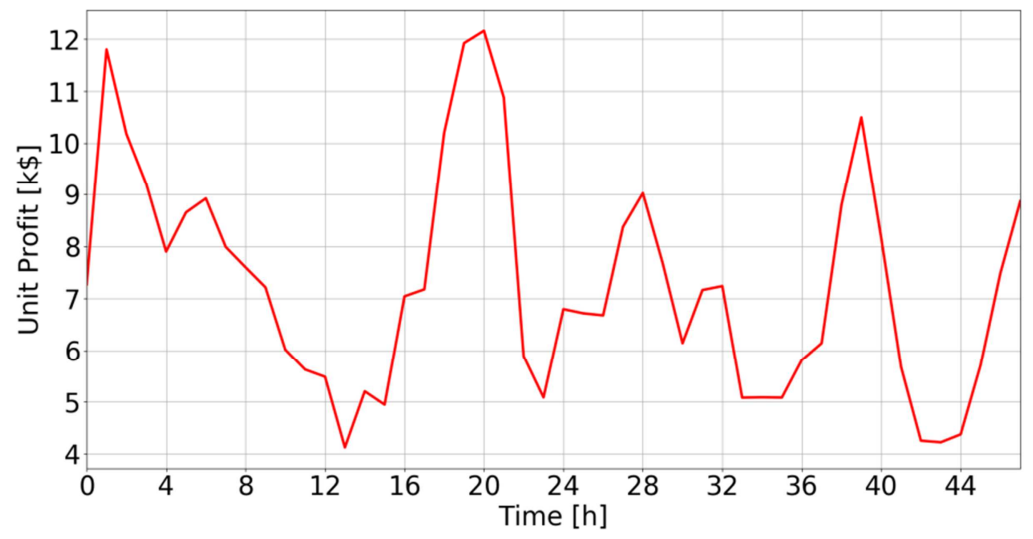

Figure 9. Profit achieved by the N-R HES unit (\$).

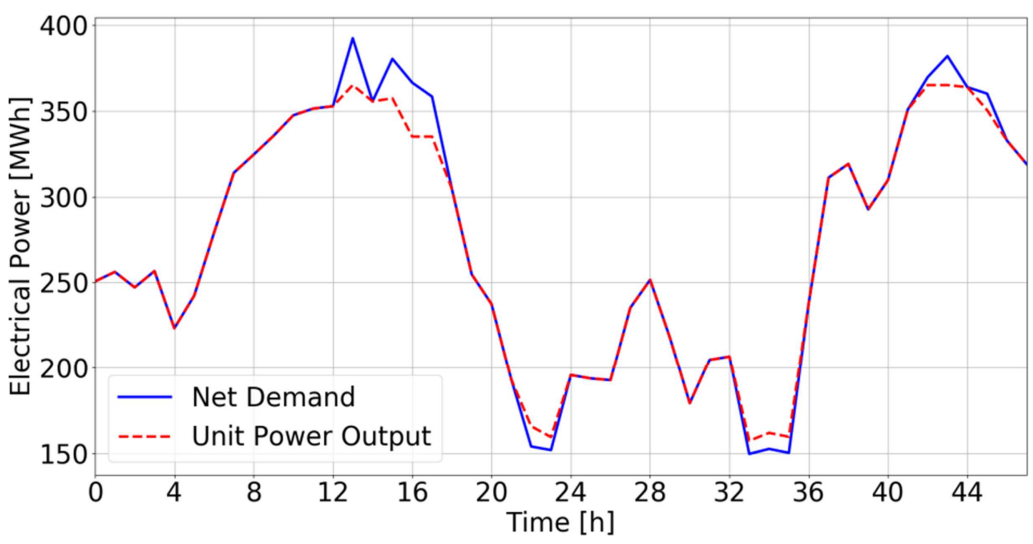

Figure 10. Electrical power (MWh). The dashed red line represents the net demand, the solid blue line represents the overall unit power output.

In Figure 11, Figure 12 and Figure 13, the SES, BOP and ES power outputs are represented (solid red lines), respectively, whereas the dashed blue lines represent the corresponding operational bounds. In Figure 14, the ES stored energy level (solid red line) is represented, whereas the dashed blue lines represent the bounds for the ES storing capacity. In Figure 10, the time frame $[12,16]$ constitutes an under-producing scenario, i.e. the unit cannot meet the peak in the net demand. In particular, though the SES and the BOP are operated at rated power level, the ES facility is almost fully discharged. Similarly, the time frame $[20,24]$ constitutes an over-producing scenario, i.e. the unit cannot reduce its electrical power output as fast as required by the load demand profile. In this case, though the SES and the BOP power outputs are close to the minimum bound of the corresponding operational ranges, the ES facility is fully charged, and it cannot absorb the power surplus. 


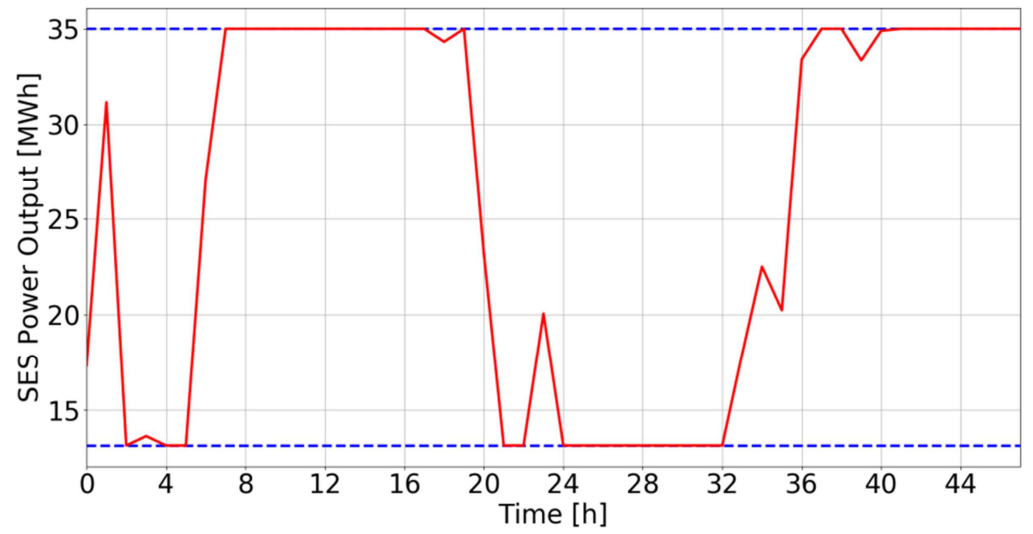

Figure 11. SES power output (MWh). The solid red line represents the instantaneous power output, the dashed blue lines represent the power operational bounds.

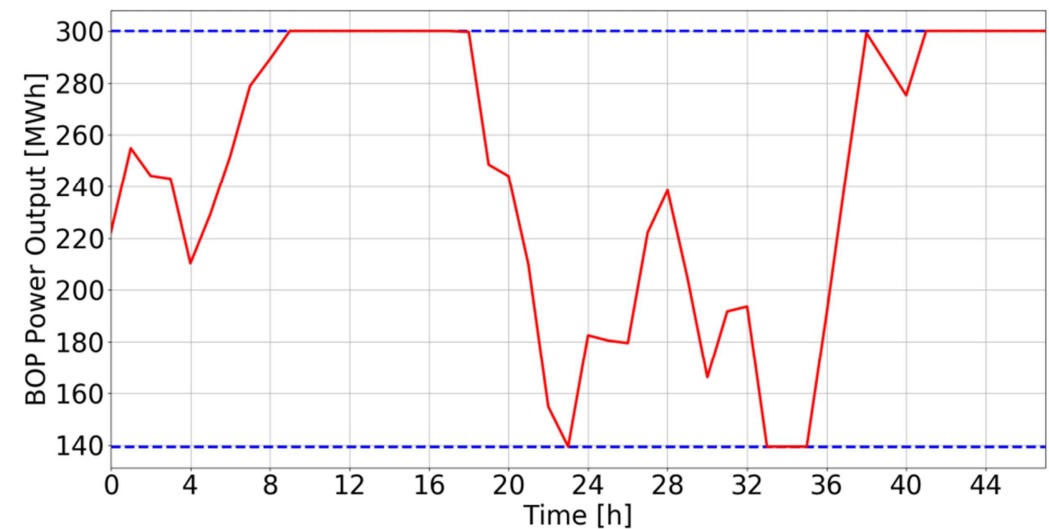

Figure 12. BOP power output (MWh). The solid red line represents the instantaneous power output, the dashed blue lines represent the power operational bounds.

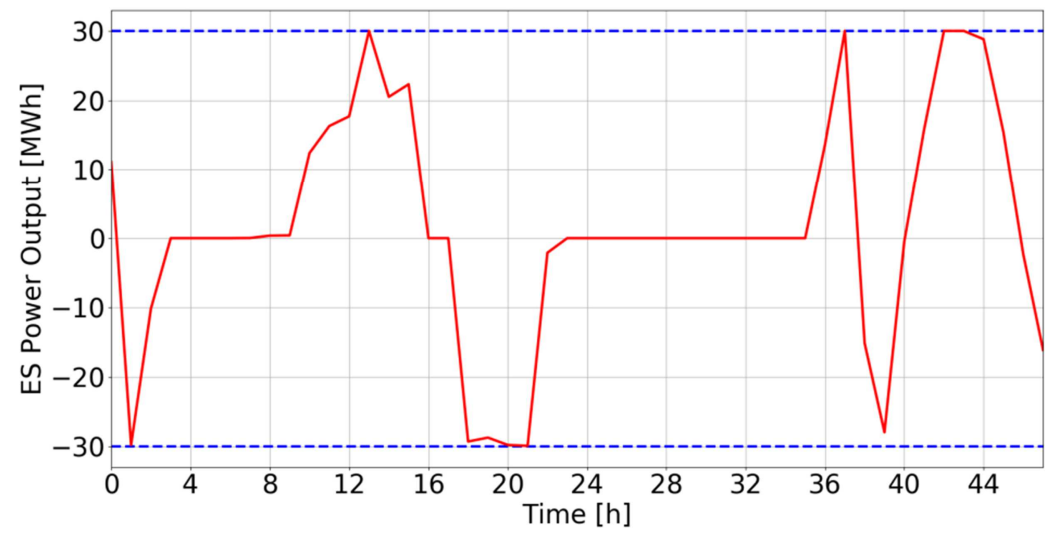

Figure 13. ES power output (MWh). The solid red line represents the instantaneous power output, the dashed blue lines represent the power operational bounds. 


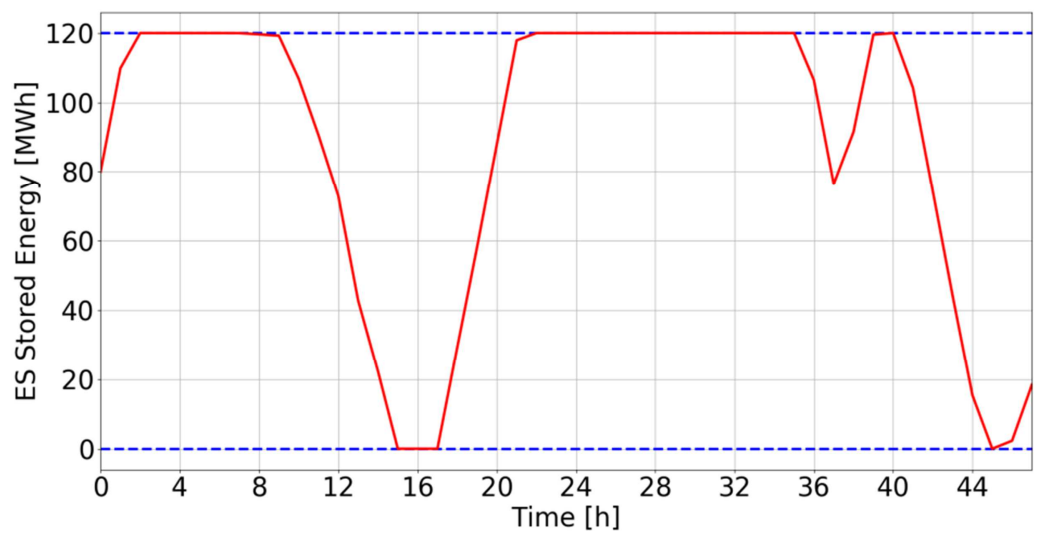

Figure 14. ES stored energy level (MWh). The solid red line represents the instantaneous value, the dashed blue lines represent the bounds for the ES storing capacity.

As for the BOP power dispatch (Figure 12), if all the PHS-produced steam was disposed to the steam turbine, the BOP would be operated as a base-load power plant, since it is characterized by the lowest operational costs (Eq.(23)). Otherwise, in the present configuration, the steam flow rate is shared with the IP, and the hydrogen is produced along with the electricity. Therefore, according to the instantaneous conditions of the unit and the instantaneous values of the unit boundary conditions (e.g., the net demand, the electricity price, ...), the unit profit is optimized by accounting for both the products. In Figure 15, the ES operation mode is represented. In Figure 16, the hydrogen production is represented.

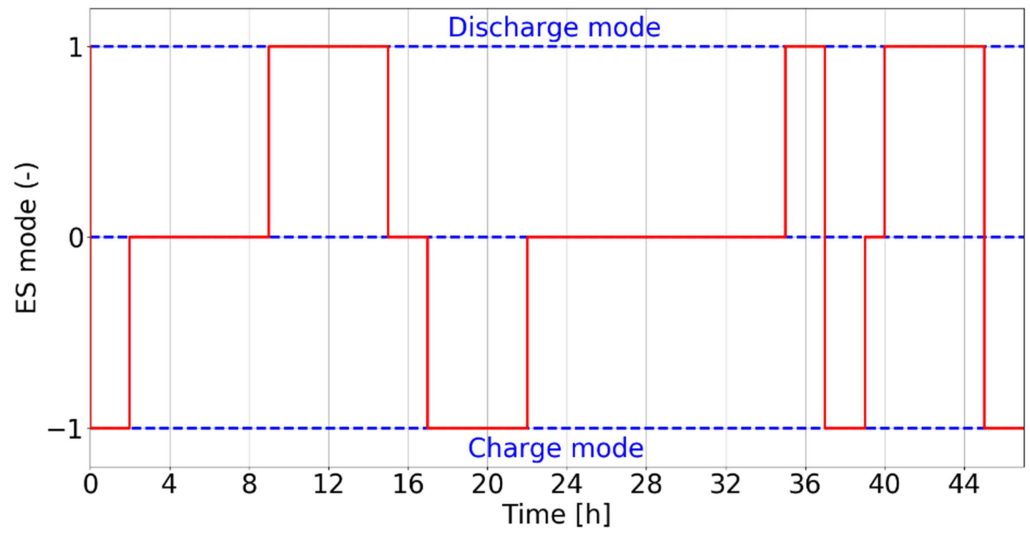

Figure 15. ES operation mode (-). The solid red line represents the instantaneous mode, the dashed blue lines represent the modes the ES can be operated (charge or discharge).

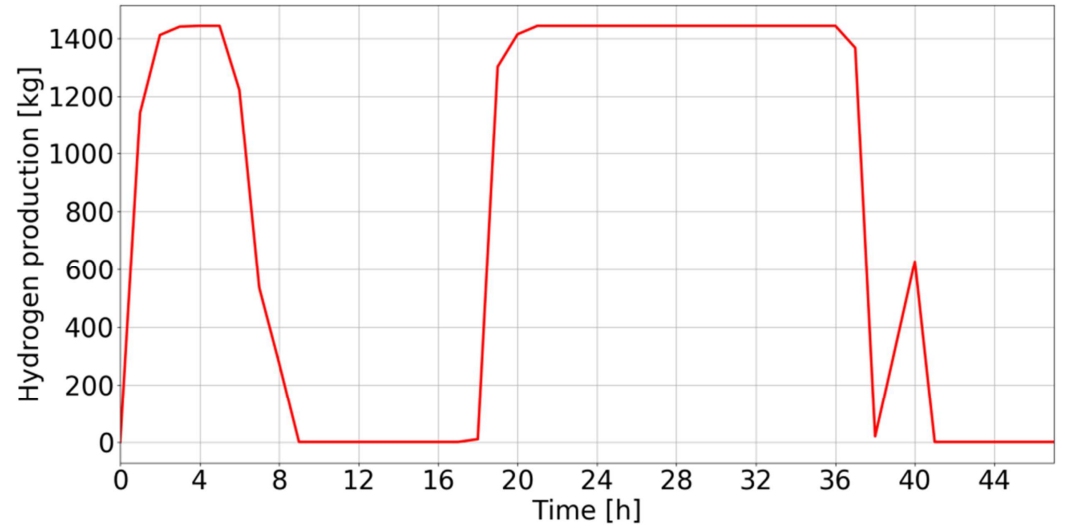

Figure 16. Hydrogen production level (kg). 


\section{Discussion}

The performance of the algorithm is summarized here based on the results for the test problem presented in the last section.

- The capacity bounds for each unit are successfully satisfied in the optimal solution.

- The ramp rate constraints for each unit are successfully satisfied in the optimal solution.

- The net demand is not always met but this is not a consequence of under performance of the algorithm. This result, in particular, is strongly affected by the adopted value for the capacity of the battery, i.e. increasing the capacity would close the gap. Moreover, the degree to which it is not met is a function of the value of lost load (VOLL) penalty, i.e. by increasing the value of the VOLL penalty, the unit power output would be force to meet the demand profile.

Additionally, the presented results reflect the fact that the dispatch priorities were imposed by artificially tuning the marginal cost of the ES component, i.e. the battery was forced to be the "last committed" by making its marginal cost the greatest of all the components. This "rule" is intended to limit the frequency of charge-discharge cycles so that the battery life is extended. (see Section 2.5 for a more detailed discussion).

\section{Future developments}

The present version of the preconditioner represents a fair approximation of the constrained optimization problem which is going to be solved in RAVEN. Anyway, the modeling of the operation strategy can still be improved. First, the cost function might be changed. At the moment, the optimal solution is obtained by maximizing the unit profit. In the next steps, the cost function will be modified to represent the unit total production cost. This would align with the latest assumption being made by team members at INL. The main improvement will concern the operation strategy of the ES facility though. In particular, in order to describe a more realistic battery commitment strategy, the electricity price forecasts will need to be introduced. The battery deployment for improved profits is usually obtained when forecast for electricity price is available, i.e. the decision of charging/discharging the battery is made according to the comparison between the instantaneous and the future values of the electricity price. From this standpoint, the battery acts more as a dispatchable "reserve" as opposed to a conventional generating unit.

\section{Acknowledgements}

For his fruitful criticism and suggestions, the authors are grateful to Francesco Ganda (ANL), who initiated the development of Monte Carlo-based optimization techniques in the ANL Nuclear Engineering Division.

\section{Reference}

[1] EPINEY, A., CHEN, J., RABITI, C., "Status on the Development of a Modeling and Simulation Framework for the Economic Assessment of Nuclear Hybrid Energy Systems (FY 16)", INL/EXT-16-39832, September 2016. 
[2] ELMQVIST, H., MATTSSON, S.E., "Modelica - The Next Generation Modeling Language an International Design Effort", Proceedings of the 1st World Congress on System Simulation (WCSS'97), Singapore, September 1-3, 1997.

[3] KIM, J.S., McKELLAR, M., BRAGG-SITTON, S.M., BOARDMAN, R.D., "Status on the Component Models Developed in the Modelica Framework: High-Temperature Steam Electrolysis Plant \& Gas Turbine Power Plant”, INL/EXT-16-40305, October 2016.

[4] GANDA, F., "Cost data and parameters for hybrid system analysis with H2 production, energy storage, nuclear plant and gas turbine", June 2017.

[5] EPINEY, A., RABITI, C., ALFONSI, A., TALBOT, P., GANDA, F., "Report on the Economic Optimization of a Demonstration Case for a Static N-R HES Configuration using RAVEN", INL/EXT-17-41915, April 2017. 


\section{Argonne}

Nuclear Engineering (NE) Division

Argonne National Laboratory

9700 South Cass Avenue, Bldg. 208

Argonne, IL 60439

www.anl.gov 